\title{
Frictional Behavior and Surface Failure of Acrylic Denture Teeth
}

\author{
C.N. RAPTIS, J.M. POWERS, and P.L. FAN \\ School of Dentistry, University of Michigan, Ann Arbor, Michigan 48109
}

The wear characteristics of acrylic denture teeth were investigated under single-and double-pass sliding. The response of acrylic teeth to sliding was that of a relatively ductile material. The wear characteristics were affected similarly by environments of water and saliva. The "enamel" surfaces showed more resistance to penetration and were less susceptible to surface damage than the "dentin" surfaces. The effect of the second pass was to increase track width and cause a more severe mode of surface failure.

J Dent Res 60(5):908-913, May 1981

Introduction.

One approach to a fundamental study of the wear of a material is to examine the frictional behavior and investigate the mechanisms that control the surface failure of the material under an applied stress that results primarily from sliding. In dentistry, such an approach has been used to study the wear characteristics of human enamel, ${ }^{1}$ dental amalgam, ${ }^{2}$ dental feldspathic porcelain, ${ }^{3}$ composite and unfilled resins, ${ }^{4}$ and pit and fissure sealants ${ }^{5}$ using the single- and doublepass sliding method.

The purpose of this study was to investigate the frictional behavior and surface failure of acrylic denture teeth. The effects of environment, types of surface (enamel and dentin), and repeated passes on the wear characteristics of these teeth were evaluated.

Received for publication April 21, 1980

Accepted for publication July 15, 1980

This research was supported in part by Research Grant DE-03416 and by Service Award DE- 07057 from the National Institute of Dental Research, National Institutes of Health, Bethesda, MD 20205.

The cooperation of Dentsply International, Inc. and Myerson Tooth Corporation in providing commercial products is acknowledged.

This research was presented in part at the annual meeting of the American Association for Dental Research in Los Angeles, CA, March, 1980.

\section{Materials and methods.}

Acrylic upper central incisor teeth (MA and $\mathrm{DA}^{\dagger}$ ) were selected for this study. The apparatus used to scratch the surface of a specimen and measure the tangential force has been described in detail elsewhere, ${ }^{6,7}$ but can be described briefly as consisting of the following: surface grinder, loading jig, friction transducer, diamond slider, and sample holder. A diamond hemisphere (360 $\mu \mathrm{m}$ in diameter) was slid across the surface of the specimens. Parallel onetraversal scratches that resulted from sliding the diamond under a normal load of 0.5 $10 \mathrm{~N}$ in varying increments were made on each specimen. The diamond slider was attached to the loading jig by a straingauge transducer that allowed the tangential force to be recorded. The specimens were mounted in a holder on the table of the surface grinder moving horizontally at a speed of $0.025 \mathrm{~cm} / \mathrm{s}$.

The study was divided into four parts: 1) The influence of liquid media on the wear characteristics of the enamel as-received surfaces of teeth DA was investigated using distilled water and filtered human saliva; 2) the wear characteristics of the enamel of teeth MA under single-pass sliding were investigated using distilled water; 3) the wear characteristics of the dentin of teeth from both manufacturers under single-pass sliding were investigated in distilled water. The dentin surface was prepared by uniformly removing material from the ridge lap area of the denture teeth to a depth of $1 \mathrm{~mm}$ and subsequent polishing; and 4) the influence of double-pass sliding on the wear characteristics of the enamel as-received

*Mold A 53, Body 95-19, Enamel 93-14, Myerson Tooth Corporation, Cambridge, MA 02139

Mold $11 \mathrm{H}$, Body 782410/MA, Enamel 790090/MB, Dentsply International, Inc., York, PA 17404 
surface of teeth from both manufacturers was studied using distilled water. Two, onetraversal scars were superimposed on each other in the same sliding direction with the same normal load.

For each combination of testing condition and brand, five replications were used. Tangential force and track-width data were collected for each run with the exception of tangential force data for double-pass runs. Track width was measured on a metallograph with the use of a calibrated eyepiece. Surface failure modes were determined under optical magnification at X200 and further studied under a scanning electron microscope. Wear scars were classified according to the degree of surface failure on a $1-4$ ordinal scale. ${ }^{8}$

The tangential force and track-width data were evaluated as a function of normal load by an analysis of variance ${ }^{9}$ that included regression and co-variance models to study the effects of medium, condition, and manufacturer.

The method used for the classification failure data was first to obtain a SpearmanKarber ${ }^{10}$ estimate of the load at which each sample failure first began to fall into the next classification. Then these values were used in a multivariate analysis of variance, ${ }^{9}$ followed by selected pairwise comparisons of each mean and the overall test of equality of means. For all the statistical analyses performed, a $95 \%$ level of confidence was used.

\section{Results.}

The track width, tangential force, and surface failure classification results for teeth DA in water were not statistically different from the respective data for runs in saliva which indicated that the wear characteristics of teeth DA were affected similarly by the two liquid environments.

Average values of tangential force for single-pass runs on the enamel and dentin groups of the two brands in water are plotted as a function of normal load in Fig. 1. Average values of track width for teeth DA are plotted as a function of normal load on log-log coordinates in Fig. 2. The mea- sured values of track width are also compared with values (straight line in Fig. 2) computed from an equation derived from a special case of Hertz's theory ${ }^{11}$ of contact

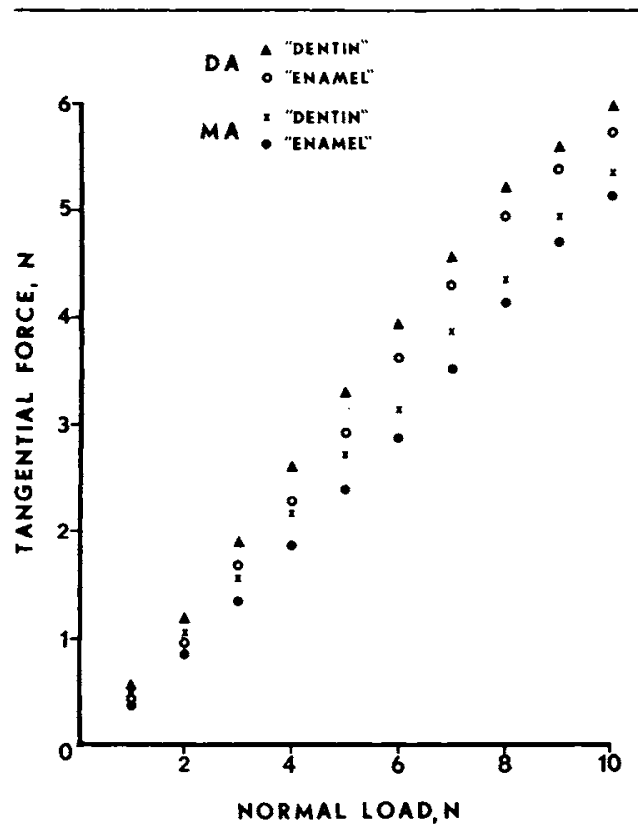

Fig. 1 - Tangential force versus normal load for single-pass sliding on the enamel and dentin surfaces of acrylic denture teeth in distilled water.

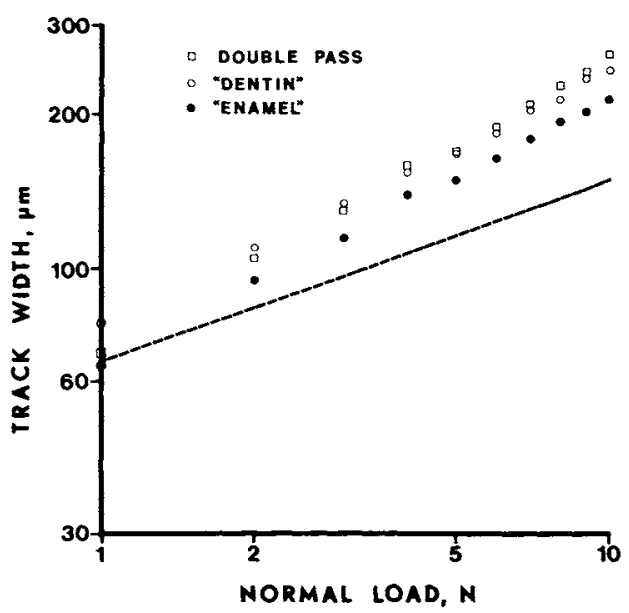

Fig. 2 - Log-log plot of track width versus normal load for teeth DA for single-pass sliding on enamel and dentin and double-pass sliding on enamel in distilled water. 
between two elastic spheres. $\S$ The trackwidth values for teeth MA were similar and produced the same ranking of the three respective groups. The comparative statistical results of track-width and tangential force data between the similar groups of the two brands are presented in Table 1 .

Photomicrographs typical of the modes of surface failure for both brands of acrylic, except for the dentin surfaces of DA, are shown in Fig. 3. A picture of the ductile mode of failure (Class 1) has been omitted. The estimated loads for surface failure transitions for the enamel surfaces of the acrylic teeth are listed in Table 2. The

$\S$ The equation used was $w=1.82(W R)^{1 / 3}$ $\left[\left(\mathrm{E}_{\mathrm{B}}\left(1-\nu_{\mathrm{A}}{ }^{2}\right)+\mathrm{E}_{\mathrm{A}}\left(1-\nu_{\mathrm{B}}{ }^{2}\right) / \mathrm{E}_{\mathrm{A}} \mathrm{E}_{\mathrm{B}}\right)\right]^{1 / 3}$ where $w$ equals track width, $W$ equals normal load, $R$ equals the radius of the diamond hemisphere, and $\nu$ and E are the Poisson's ratio and Young's modulus for acrylic (A) and diamond (B), respectively. In this equation Poisson's ratio and Young's modulus for diamond were 0.30 and $930 \mathrm{GN} / \mathrm{m}^{2}$, respectively. Poisson's ratio and Young's modulus for acrylic were 0.41 and $2.65 \mathrm{GN} / \mathrm{m}^{2}$, respectively. changes in classification of surface failure as a result of the second pass are shown in Fig. 4. The increase in the extent of surface damage at the section of wear tracks corresponding to the second-pass region is evident. Fig. 5 shows the modes of surface failure observed for the dentin surfaces of DA. The difference in the morphology of the wear scars of the dentin surfaces of DA from all the other surfaces of both brands is noticeable.

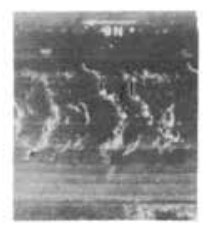

CLASS 2

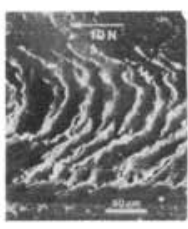

CLASS 3

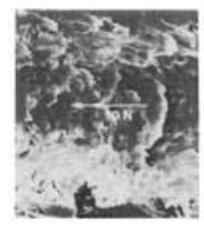

CLASS 4
Fig. 3 - SEM photomicrographs of wear tracks showing typical modes of surface failure of acrylic denture teeth except dentin DA group.

TABLE 1

DATA FROM ANALYSIS OF VARIANCE FOR LN TRACK WIDTH $V S$. LN NORMAL LOAD AND TANGENTIAL FORCE $V S$. NORMAL LOAD BETWEEN THE BRANDS OF ACRYLIC TEETH IN WATER

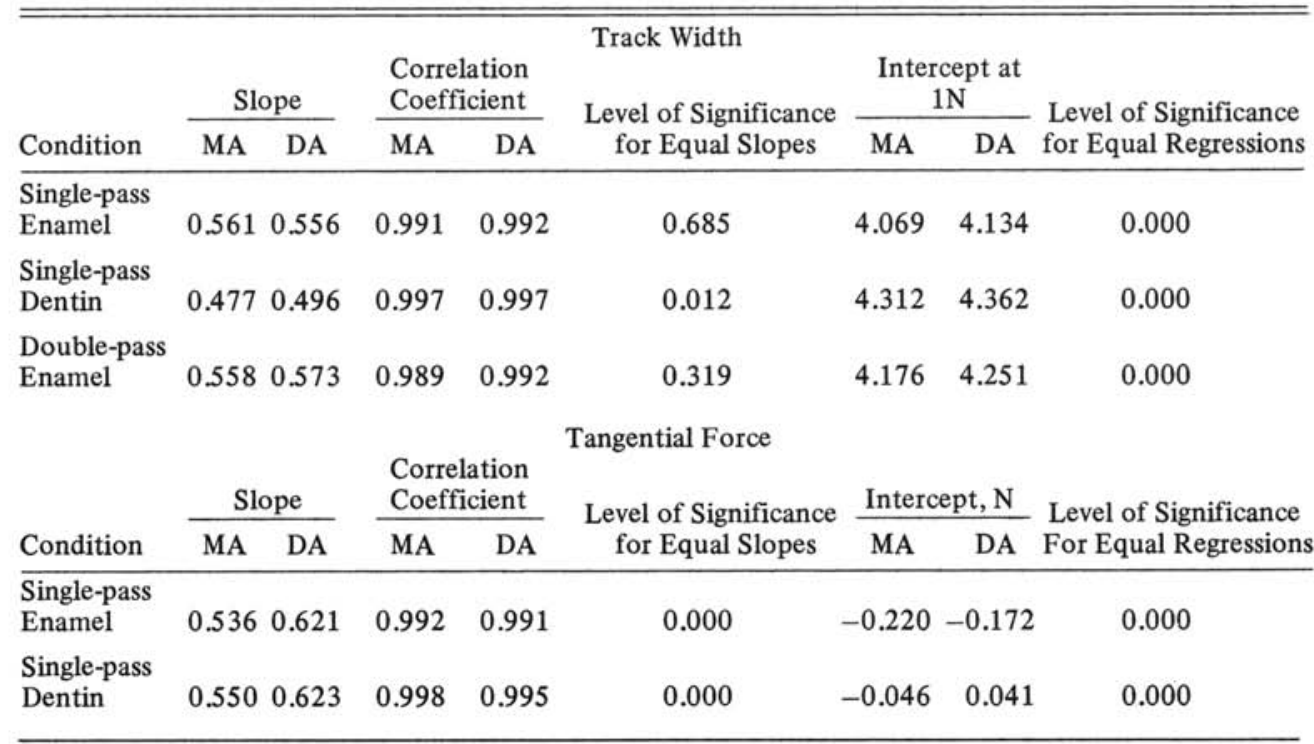


TABLE 2

ESTIMATED LOADS FOR SURFACE FAILURE TRANSITIONS FOR "ENAMEL" SURFACES OF ACRYLIC TEETH (MA AND DA)

\begin{tabular}{|c|c|c|c|c|c|c|}
\hline \multirow[b]{3}{*}{ Testing } & \multicolumn{6}{|c|}{ Estimated Transition Load* $\mathrm{N}$} \\
\hline & \multicolumn{2}{|c|}{ Classes 1 to 2} & \multicolumn{2}{|c|}{ Classes 2 to 3} & \multicolumn{2}{|c|}{ Classes 3 to 4} \\
\hline & MA & DA & MA & DA & MA & DA \\
\hline Single-pass & 5.65 & 4.85 & -- & $10.10^{\dagger}$ & -- & -- \\
\hline Double-pass & 2.70 & 2.30 & 5.50 & 4.50 & 8.30 & 6.70 \\
\hline
\end{tabular}

*Overall statistical test: $\mathrm{F}=5.13, \mathrm{p}=0.043$ for single pass, $\mathrm{F}=11.75, \mathrm{p}=0.006$ for double pass.

tThe mean is greater than $10 \mathrm{~N}$, because some of the replications did not reach class failure 3 . For these replications, the arbitrary assumption was made that the samples would have failed at the load of $11 \mathrm{~N}$; therefore, for these samples the computational value of $11 \mathrm{~N}$ was assigned.

\section{Discussion.}

Acrylic tooth material, a linear polymer with crosslinking agents added, responded to sliding in a principally ductile manner. The extent of wear varied according to the applied normal load. In general, low values of track width were concurrent with low tangential force values and limited surface damage, while larger track-width values were indicative of higher values of tangential force and more severe surface failure. Within most of the range of the normal loads tested, the surface of the acrylic teeth accommodated the strain in a ductile mode. At higher loads when strain could not be accommodated entirely by plastic deformation, the surface responded with tensile cracks. The data of track width and tangential force appeared to be directly related, suggesting that penetration of the diamond slider into the resin is principally responsible for the tangential force. In general, the trackwidth values measured were considerably higher than the values predicted by the Hertzian theory of two elastic bodies. It is suggested that these high values reflect the apparent ductility of the material which is not taken into account in Hertz's model. The considerably higher tangential force values recorded reflect the contribution of plowing friction that resulted also from this ductility.

As a group, the enamel surfaces of both brands were damaged less, the frictional resistance was smaller, and the resistance to penetration was higher than the dentin surfaces. The preparation of the dentin samples involved removal of the external enamel layer and subsequent polishing. The dentin subsurface exposed is not equally resistant to surface failure, possibly as a result of the removal of the external layer consisting of material with a higher amount of crosslinking introduced during manufacturing of the teeth. The clinical implications of these comparative results between the enamel and dentin surfaces are important, since it is rather common practice to expose the dentin area by grinding the denture teeth into a desired occlusal scheme.

Track widths in the double-pass regions were higher than those in the single-pass regions, particularly at higher loads, and were coupled with a more severe mode of surface failure in the double-pass regions. It is suggested that subsurface damage caused by the first traversal is propagated by the second pass. The double-pass results provide an insight to the nature of subsurface damage that may not be apparent from single-pass tests. The results indicated that there is a difference in wear characteristics as determined by the single- and double-pass sliding between all the pairs of groups of the two brands.

Under single-pass sliding, the enamel group of teeth DA had higher values of track width, higher values of tangential force, and lower estimated values of transition load than the enamel group of teeth MA. A subtle morphological difference that was noted on the wear tracks of the enamel among the two brands was the presence of "snakeskin" projections on the surface of the wear tracks of teeth MA. It is uncertain if the 


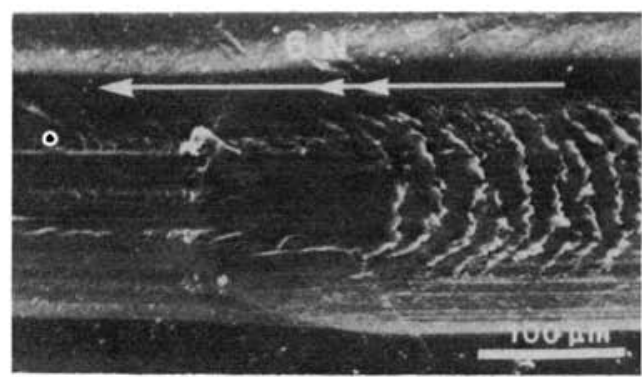

CLASS 2 TO 3

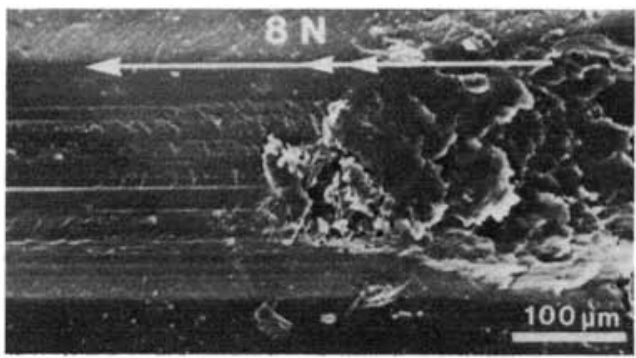

CLASS 2 TO 4

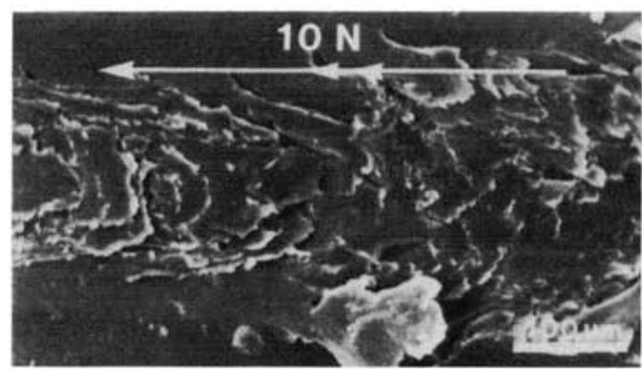

CLASS 3 TO 4

Fig. 4 - Surface failure transitions of acrylic denture teeth from double- to single-pass sliding on enamel.

differences seen in the data could partially or entirely be attributed to this morphological differentiation. The projections persisted on the surface of the wear tracks until Class 3 failure was observed. A comparison of the track-width and tangential force results among the dentin groups of the two manufacturers resulted in the same ranking, indicating that the dentin surface of DA was more susceptible to penetration and surface

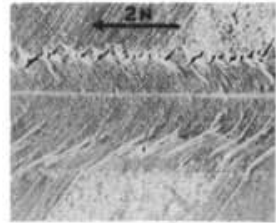

CLASS 1

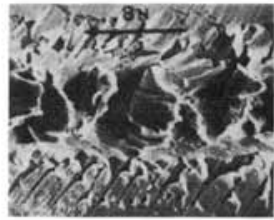

CLASS 3

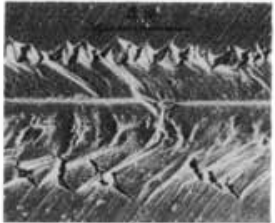

CLASS 2

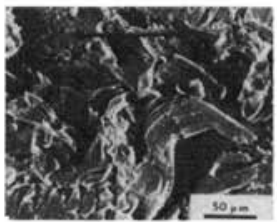

CLASS 4
Fig. 5 - SEM photomicrographs of wear tracks showing surface failure of single-pass sliding on the dentin surface of DA.

damage than that of MA under single-pass sliding. However, the previously discussed difference in the modes of surface failure of dentin DA from all the other groups should warrant some caution in any comparisons. The results from the double-pass sliding on enamel for the two brands were consistent with the ranking of the two brands, as established by the enamel and dentin singlepass data.

\section{Conclusions.}

The frictional behavior and surface failure of acrylic denture teeth under sliding were used to study the influence of environment, enamel versus dentin surfaces, and repeated passes on the wear characteristics. The response of acrylic teeth to sliding was characteristic of a relatively ductile material. The wear characteristics as determined by single-pass sliding were affected similarly by environments of water and saliva. The enamel surfaces of the teeth were less susceptible to surface damage and surface penetration than the dentin surfaces under single-pass sliding. The damage resulting from double-pass sliding on the enamel surfaces was more severe than damage from single-pass sliding. As a group the enamel and dentin surfaces of teeth MA suffered less extensive damage in single-pass sliding than the respective surfaces of teeth DA. Double-pass results of the enamel surfaces of 
the two brands were consistent with this ranking.

\section{REFERENCES}

1. POWERS, J.M.; CRAIG, R.G.; and LUDEMA, K.C.: Frictional Behavior and Surface Failure of Human Enamel, J Dent Res 52:1327-1331, 1973.

2. ROBERTS, J.C.; POWERS, J.M.; and CRAIG, R.G.: Wear of Dental Amalgam, $J$ Biomed Mater Res 11:513-523, 1977.

3. MILLER, G.R.; POWERS, J.M.; and LUDEMA, K.C.: Frictional Behavior and Surface Failure of Dental Feldspathic Porcelain, Wear $31: 307-316,1975$.

4. POWERS, J.M.; ROBERTS, J.C.; and CRAIG, R.G.: Wear of Filled and Unfilled Dental Restorative Resins, Wear 39:117-122, 1976.

5. ROBERTS, J.C.; POWERS, J.M.; and CRAIG,
R.G.: Wear of Commercial Pit and Fissure Sealants, J Dent Res 56:692, 1977.

6. POWERS, J.M. and CRAIG, R.G.: Wear of Fluorapatite Single Crystals. I. A Method for Quantitative Evaluation of Wear, $J$ Dent Res 51:168-176, 1972.

7. POWERS, J.M. and CRAIG, R.G.: Wear of Fluorapatite Single Crystals. II. Frictional Behavior, J Dent Res 51:605-610, 1972.

8. RAPTIS, C.N.: Wear Characteristics of Prosthetic Denture Teeth, Ann Arbor: University of Michigan, 1980,170 p., Master's Thesis.

9. University of Michigan, Statistical Research Laboratory: A Manual of Elementary Statistics Using MIDAS, Ann Arbor, MI: Statistical Research Laboratory, 1975, $301 \mathrm{p}$.

10. FINNEY, D.J.: Statistical Methods in Biological Assay, 2nd ed., New York: Hafner, $1964,668 \mathrm{p}$.

11. HERTZ, H.R.: On the Contact of Elastic Solids (in German), $J$ Reine Angew Math 92: 156-171, 1881.

\section{CALL FOR ABSTRACTS}

Dental Health Section

American Public Health Association

The Dental Health Section of the American Public Health Association is inviting papers on a broad range of dental public health subjects to be submitted for presentation at the Association's 109th Annual Meeting, which will be held in Los Angeles, California, November 1-5, 1981.

Special emphasis will be placed on those areas related to this year's annual theme"Energy, Health, and the Environment."

Information can be obtained by writing to:

Dr. David I. Rosenstein

University of Oregon Health Sciences Center

School of Dentistry

611 SW Campus Drive

Portland, OR 97201 